Environmental Modeling \& Assessment

June 2016, Volume 21, Issue 3, Pages 371-389

http://dx.doi.org/10.1007/s10666-015-9486-y

http://archimer.ifremer.fr/doc/00300/41073/

(c) Springer International Publishing Switzerland 2015

\title{
The Cost of Co-viability in the Australian Northern Prawn Fishery
}

\author{
Gourguet Sophie ${ }^{1,{ }^{*}}$, Thébaud Olivier ${ }^{1,2}$, Jennings Sarah ${ }^{3,4}$, Little L. Richard ${ }^{4,5}$, \\ Dichmont Catherine M. ${ }^{6}$, Pascoe Sean ${ }^{4}$, Deng Roy A. ${ }^{4}$, Doyen Luc ${ }^{7}$
}

${ }^{1}$ IFREMER, UMR M101, AMURE, Unité d'Economie Maritime, BP 70, F-29280, Plouzané Cedex, France

${ }^{2}$ School of Economics and Finance, Queensland University of Technology, Brisbane, Australia

${ }^{3}$ Tasmanian School of Business and Economics, University of Tasmania, Private Bag 84, Hobart, 7000, Australia

${ }^{4}$ Centre for Marine Socioecology, University of Tasmania, Private Bag 129, Hobart, 7000, Australia

${ }^{5}$ CSIRO Oceans and Atmosphere Flagship, PO Box 1538, Hobart, TAS, 7001, Australia

${ }^{6}$ CSIRO Oceans and Atmosphere, PO Box 2583, Brisbane, QLD, 4001, Australia

${ }^{7}$ CNRS, GREThA, University of Bordeaux, Avenue Léon Duguit, 33608, Pessac Cedex, France

* Corresponding author : Sophie Gourguet, email address : sophie.gourguet@ifremer.fr

\begin{abstract}
:
Fisheries management must address multiple, often conflicting objectives in a highly uncertain context. In particular, while the bio-economic performance of trawl fisheries is subject to high levels of biological and economic uncertainty, the impact of trawling on broader biodiversity is also a major concern for their management. The purpose of this study is to propose an analytical framework to formally assess the trade-offs associated with balancing biological, economic and non-target species conservation objectives. We use the Australian Northern Prawn Fishery (NPF), which is one of the most valuable federally managed commercial fisheries in Australia, as a case study. We develop a stochastic coviability assessment of the fishery under multiple management objectives. Results show that, due to the variability in the interactions between the fishery and the ecosystem, current management strategies are characterized by biological and economic risks. Results highlight the trade-offs between respecting biological, economic and non-target species conservation constraints at each point in time with a high probability and maximizing the net present value of the fishery.
\end{abstract}

Keywords : Bio-economic modeling ; Co-viability cost ; Conflicting management objectives ; Trawling impacts ; Uncertainty ; Northern prawn fishery 


\section{Introduction}

There is growing evidence that fishing activities, such as trawling, affect not only the target stocks, but also populations of non-target species [35]. As Zhou et al [59] pointed out "it is impossible to fish without impacting biodiversity" irrespective of the fishing method used. The use of fishing gears with low selectivity induces catches of non-target fishes (i.e. by-catch and by-product) or unwanted length grades of the target species, while selective approaches might alter the population or community structure [29]. Catches of by-catch species are mostly discarded and data analysed by Alverson et al [4] suggest that survival of most discarded species is low. Discards represent a significant proportion of global marine catches and are generally considered to constitute waste, and suboptimal use of fishery production [39]. As a result, the management and mitigation of by-catch is a pressing issue facing commercial fishing worldwide [35]. In the case of demersal trawling, such as prawn trawling, fishing activities can be particularly damaging to non-target species and habitats. Trawl nets used to catch prawns have small mesh and may be towed along a biologically-diverse seabed. This activity results in large quantities of discarded by-catch, including impacts on endangered or vulnerable species, such as turtles, sharks, rays, sea snakes, sawfishes and seahorses. Alverson et al [4] estimated that around one-third of the world's discards are associated with prawn trawl fishing, and Kelleher [39] estimated that on average $62.3 \%$ of the weight of total prawn trawl catch is discarded.

Marine fisheries management is characterized by multiple, often conflicting objectives [13, 15], reflecting biological, ecological and economic viewpoints for instance. As stressed by Cheung and Sumaila [14], understanding the trade-offs between various objectives is important in evaluating policies to manage ecosystems and fisheries. In this context, the stochastic co-viability approach $[7,22,31,42]$ has been proposed as a relevant framework for quantifying the performance of fishery management strategies against multiple management objectives.

The objective of this paper is to propose a model-based framework which allows characterization of the tradeoffs associated with alternative management strategies in a mixed fishery, with specific emphasis on the consequences of pursuing biological, economic and non-target species conservation objectives. The framework is applied to the Australian Northern Prawn Fishery (NPF). We expand on the stochastic co-viability framework of analysis proposed in Doyen et al [24] and applied by Gourguet et al [31] to a simplified bio-economic model of the NPF. In particular, we consider the implications of including a formal non-target species conservation constraint for the co-viability of fishing management strategies. In this study, sea snake catches are used as a proxy to assess impacts of the fishery on sea snakes. Results of this assessment point to the fact that pursuing conservation objectives based on non-target sea snakes, as defined in this work, along with objectives of reducing biological and economic risks may lead to a need to revise current management strategies, with a resulting cost in terms of lost economic returns. Our approach allows this cost to be quantified and analysed. 


\section{Stochastic co-viability of a fishery under multiple objectives}

In a more formal way, the fishery is represented as an uncertain control dynamic system in discrete time as follows:

$$
\mathrm{x}(t+1)=f(\mathrm{x}(t), \mathrm{u}(t), \omega(t))
$$

where $\mathrm{x}(t)$ represents the biological resource stock at time $t$ while $\mathrm{u}(t)$ is the control or decision and $\omega(t)$ the uncertainties affecting the system at time $t$. Bio-economic viability constraints inspired by Béné et al [8] can be defined as in equation (2):

$$
\left\{\begin{array}{lr}
\mathrm{x}(t) \geq \mathrm{x}^{\text {min }} \geq 0 & \forall t=t_{0}, \ldots, T, \\
\pi(\mathrm{x}(t), \mathrm{u}(t)) \geq \pi^{\text {min }} & \forall t=t_{0}, \ldots, T, \\
\operatorname{Impact}(\mathrm{u}(t)) \leq \operatorname{Impact}^{\text {max }} & \forall t=t_{0}, \ldots, T .
\end{array}\right.
$$

where $\mathrm{x}^{\min }$ is the minimum resource level to maintain, reflecting a biological management objective. $\pi(\mathrm{x}(t), \mathrm{u}(t))$ represents the net benefit (or profit) from the harvesting of the resource $\mathrm{x}(t)$ given the decision $\mathrm{u}(t)$, and $\pi^{\mathrm{min}}$ is the minimum profit to guarantee in all time periods, based on an economic management objective. Impact corresponds to a proxy for fishing impacts on non-target species and Impact $^{\max }$ is the maximum fishing impact allowed, corresponding to a non-target species conservation objective.

These constraints characterize an acceptable sub-region of the phase space within which the fishery evolves. A particular trajectory followed by the fishery will be called viable if it remains in this region during the prescribed period of time. The percentage of viable trajectories gives the estimated viability probability. Given a control or decision sequence $\mathrm{u}($.$) , the probability of co-viability CVA(u) of a fishery system, considering the multiple$ constraints defined in equation (2), is then given by:

$$
\mathrm{CVA}\left(\mathrm{u}\left(t_{0}\right), \ldots, \mathrm{u}(T)\right)=\mathbb{P}\left(\text { constraints }(2) \text { are satisfied for } t=t_{0}, \ldots, T\right) \text {. }
$$




\title{
3 Application to the Northern Prawn Fishery
}

\author{
3.1 The Australian Northern Prawn Fishery
}

The Northern Prawn Fishery (NPF), located off Australia's northern coast and established in the late 1960s, is a multi-species trawl fishery which harvests several high-value prawn species, each with different biological dynamics and levels of variability. The fishery derives its revenue from an unpredictable naturally fluctuating resource, the white banana prawn (Penaeus merguiensis), and a more predictable resource comprising two tiger prawn species (grooved tiger prawn, Penaeus semisulcatus and brown tiger prawn, Penaeus esculentus). These three species account for $95 \%$ of the total annual landed catch value of the fishery [1]. Blue endeavour prawns (Metapenaeus endeavouri) are also caught as by-product [57].

Trawl impacts on habitats and benthos communities are usually quantified at small scales instead of fishery management scales. In this context, Ellis et al [26] and Pitcher et al [48] provide some examples of how to assess trawl impacts at fishery management scales. Haywood et al [36] have highlighted that trawling for prawns is a highly targeted activity in the NPF; consequently trawl impacts on benthos communities are restricted to a small proportion of the fishery. The seabed fauna in their experimental area was made up mostly of mobile animals and the authors surmise that recovery takes place mainly through immigration from adjacent untrawled areas. In addition, Bustamante et al [11] suggest that impacts to benthic habitats are likely to be low at current effort levels (limited to 52 fishing licenses). Broader biodiversity impacts of the NPF involve high proportions of by-catch and interactions with protected and endangered species. By-catch in the NPF consists of small fish, invertebrates, sponges, other megabenthos, rays, sawfish, sharks, sea snakes and turtles [54]. Many of these species are dead when discarded, or have a low survival rate [37].

Management of the NPF is aimed at achieving maximum economic yield (MEY), which reflects both stock conservation and economic performance objectives. However, demonstrating ecological sustainability is a legislative and market requirement for an increasing number of fisheries worldwide, particularly demersal trawl fisheries such as the NPF [33]. The Australian Fisheries Management Act 1991 and Environment Protection and Biodiversity Conservation Act 1999 require that negative effects on endangered species be avoided, catches of non-target species be reduced to a minimum, and the long-term sustainability of by-catch and by-product populations be demonstrated. The Marine Stewardship Council ${ }^{1}$ (MSC) certifies sustainable practices and requires limited effects on non-target species. In certifying the fishery in November 2012, it acknowledged efforts to limit fishing impacts on the ecosystem, although some impacts remain. Reducing these impacts further would however involve tradeoffs between non-target species conservation objectives and other policy objectives, notably maximizing economic yield from the fishery, which is a key management focus for this fishery.

\footnotetext{
1 The MSC is an international non-profit organisation established to promote solutions to the problem of overfishing.
} 
3.2 The bio-economic model

This study expands upon a bio-economic model, presented in Gourguet et al [32] and derived from Dichmont et al $[17,18]$, Punt et al [49] and Punt et al [50].

\subsubsection{Prawn population dynamics}

The model includes explicit population dynamics of grooved $(s=1)$ and brown $(s=2)$ tiger prawns and blue endeavour prawns $(s=3)$. Population dynamics are based on a multi-species size- and sex-structured model of each species. The model allows for week-specificity in recruitment, spawning, availability and fishing mortality. Annual recruits in the fishery for species $s=1,2$ and 3 are assumed to be related to the spawning stock size index of species $s$ for the previous year, according to a Ricker stock-recruitment relationship fitted assuming temporally correlated environmental variability and down-weighting recruitments, as described in Punt et al [49] and Punt et al [50].

The annual spawning stock size indices $\mathrm{S}_{s}(y(t))$ of the grooved and brown tiger and blue endeavour prawns $\left(s=1,2\right.$ and 3) for the year ${ }^{2} y(t)$ are calculated as in Punt et al [49], and described in appendix A.1.

White banana prawns (species $s=4$ ) are represented without an explicit density-dependence mechanism, due to their highly variable recruitment and in the absence of a defined stock-recruitment relationship. The biomass of this species is thus modeled as a uniform i.i.d. random variable, described in appendix A.2.

\subsubsection{Harvesting and economics}

The Northern Prawn Fishery consists of two sub-fisheries that are to a large degree spatially and temporally separate. The 'banana prawn sub-fishery' is a single-species fishery based on the white banana prawn, while the 'tiger prawn sub-fishery' is a mixed-species fishery targeting grooved and brown tiger prawns, as well as blue endeavour prawn which is caught as by-product. Two fishing strategies can be identified within the tiger prawn sub-fishery, one associated with catching grooved tiger prawns (hereafter called the 'grooved tiger prawn fishing strategy', $f=1$ ) and the other associated with catching brown tiger prawns (hereafter called the "brown tiger prawn fishing strategy', $f=2)$. Both tiger prawn fishing strategies result in by-catch of tiger and endeavour prawn species.

Catches are estimated by fishing strategy (with $f=1,2$ for the grooved and brown tiger prawn fishing strategies, respectively), and by sub-fishery (with $f=1+2$ for the tiger prawn sub-fishery and $f=3$ for the banana prawn subfishery). Weekly catches $C_{s, l, f}(t)$ of species $s=1,2$ and 3 in length-class $l$ by tiger prawn fishing strategies $(f=1,2)$; and annual catches $C_{4,3}(y(t))$ of white banana prawns $(s=4)$ by the banana prawn sub-fishery $(f=3)$ for the year $y(t)$ are defined in appendix A.3.

The economic component of the model estimates the flow of costs and revenues from fishing over time. Appendix A.4 gives details on the calculation of the total annual profit of the whole fishery $\pi(y(t))$ for year $y(t)$.

2 Year $y(t)$ is a function of week $t$, where weeks are numbered $1, \ldots, 52,53, \ldots, 102,103, \ldots$ 
The net present value (NPV) of the flow of profits over simulation time is calculated as the aggregated value of discounted annual profits and is given by:

$$
\mathrm{NPV}=\sum_{y(t)=1}^{T-1} \frac{\pi(y(t))}{(1+\mathrm{r})^{y(t)-1}}+\frac{\pi(T)}{\mathrm{r}(1+\mathrm{r})^{T-1}} .
$$
displayed.

Table 1 Symbols, values and descriptions of the sub-indices used in the study

\begin{tabular}{lll}
\hline Symbol & Value & Description \\
\hline \multirow{4}{*}{$s$} & 1 & grooved tiger prawn species \\
& 2 & brown tiger prawn species \\
& 3 & blue endeavour prawn species \\
& 4 & white banana prawn species \\
\hline$l$ & 1 to 41 & 1-mm length-class between 15 to $55 \mathrm{~mm}$ \\
\hline & 1 & tiger prawn fishing strategy targeting grooved tiger prawns \\
& 2 & tiger prawn fishing strategy targeting brown tiger prawns \\
& $1+2$ & tiger prawn sub-fishery which comprises the two tiger prawn fishing strategies \\
& 3 & banana prawn sub-fishery which targets white banana prawns \\
\hline
\end{tabular}

where $\mathrm{r}$ is the discount rate (assumed to be 5\%, as in [50]), and $T$ is the terminal year of the simulation. The last term of the equation implies a sustainability condition in the terminal year as in [49] and acts to avoid stock collapses when maximizing the NPV.

Sub-indices used in this study are summarized in table 1 where their symbols, values and descriptions are

For further details on the bio-economic model and parameter values, see Gourguet et al [32].

\subsubsection{Impacts of fishing on non-target species: the case of sea snakes}

NPF operations interact with several groups of threatened, endangered and protected (TEP) species including sea snakes, turtles, elasmobranchs (such as sawfishes, sharks and rays), and syngnathids (seahorses and pipe fishes) [2]. The amount of by-catch species caught in prawn trawl nets has been significantly reduced since 2000 through the mandatory introduction of Turtle Excluder Devices (TEDs) and By-catch Reduction Devices (BRDs). Nets with TEDs are particularly effective at reducing catches of larger animals such as turtles (by 99\%), large rays and sharks (by $94 \%$ and $86 \%$, respectively); in contrast, BRDs are more effective at excluding small fishes [10]. However, Brewer et al [10] estimate that nets with a combination of a TED and BRD reduced the catches of sea snakes (Hydrophiidae) by only 5\%. There are 11 endemic species among the 35 sea snake species recorded in Australian waters, which represents more than half of the worlds 62 described species. Most Northern Australian sea snake species live in shallow waters less than 40 meters deep with low topographic relief, typical of the prawn trawl grounds in the NPF [56, 28]. Furthermore, sea snakes have been considered more vulnerable to fishing impacts than many fish species, mainly because they cannot breathe underwater and have a low productivity [28]. There has been growing concern over the impact of prawn trawling in the NPF on sea snake populations since their addition to the 'Listed Marine Species' by the Department of Environment and Water Resources in 2000. Moreover, sea snakes are protected species under the federal Environmental Protection and Biodiversity Conservation Act 1999 (EPBC 
Act) and the Northern Prawn Fishery industry is thus required to demonstrate that its activity does not adversely impact these marine animals [43]. Based on these concerns, trawling impacts on sea snakes were considered in this study.

In the absence of sufficient data, we could not explicitly model the dynamics of sea snake populations. Given that sea snake catches appear to be significantly correlated with fishing effort in the NPF, we choose to model the impacts of trawling on sea snakes by estimating their catches by the fishery from the fishing efforts of the tiger and banana prawn sub-fisheries. Although the tiger and banana prawn sub-fisheries both use gear that can be broadly classified as demersal otter trawls, their method of gear deployment differs. In the tiger prawn sub-fishery, the trawl is generally lowered over suitable prawn habitat to fish as close as possible to the seabed, and is towed for three to four hours. In contrast, in the banana prawn sub-fishery the trawl gear is deployed for less than an hour on a prawn aggregation (or 'boil') in the water column identified using an echo sounder [34]. The amount of by-catch thus varies by sub-fishery, discard biomass being generally lower in the banana prawn sub-fishery due to operators targeting prawn aggregations [34].

We consider total annual sea snake catch $\mathrm{C}_{\text {snake }}(y(t))$ as an indicator of the impacts of fishing on sea snakes:

$$
\mathrm{C}_{\text {snake }}(y(t))=\mathrm{C}_{\text {snake }, 1+2}(y(t))+\mathrm{C}_{\text {snake }, 3}(y(t)) \text {. }
$$

Annual sea snake catches $\mathrm{C}_{\text {snake, } f}(y(t))$ by sub-fishery $f$ (with $f=1+2$ corresponding to the tiger prawn subfishery and $f=3$ to the banana prawn sub-fishery) is estimated based on data available in [6], using the following specification:

$$
\left\{\begin{array}{l}
\mathrm{C}_{\text {snake }, 1+2}(y(t))=a_{1+2}^{r e g} \mathrm{E}_{1+2}(y(t))+\xi_{1+2}(y(t)), \\
\mathrm{C}_{\text {snake }, 3}(y(t))=a_{3}^{r e g} \mathrm{E}_{3}(y(t))+\xi_{3}(y(t))
\end{array}\right.
$$

with

$$
\left\{\begin{array}{l}
\xi_{1+2}(y(t)) \sim \mathcal{N}\left(0, \sigma_{1+2}^{2}\right), \\
\xi_{3}(y(t)) \sim \mathcal{N}\left(0, \sigma_{3}^{2}\right) .
\end{array}\right.
$$

where $\mathrm{E}_{1+2}(y(t))$ and $\mathrm{E}_{3}(y(t))$ are respectively the annual effort of tiger and banana prawn sub-fisheries during the year $y(t) . a_{1+2}^{\text {reg }}$ and $a_{3}^{\text {reg }}$ are the coefficient values from the linear regressions by sub-fishery $f=1+2,3$ (given in table 7 in appendix C). $\xi_{1+2}(y(t))$ and $\xi_{3}(y(t))$ are the residual terms for the year $y(t)$ and are assumed to be independent normally distributed random variables with mean equal to zero and variance $\sigma_{1+2}$ and $\sigma_{3}$, respectively (see appendix C).

Trials of a Popeye Fishbox BRD revealed that this design could deliver an $87 \%$ reduction in catches of sea snakes when installed at 70 meshes from the cod-end drawstrings [51]. However, the majority of the fleet places currently their BRDs at the maximum allowable distance forward of the cod-end [43] in the belief that prawns will escape if the BRD is placed closer to the cod-end [43]. To model a progressive adoption over time of these more effective BRDs, we reduced progressively the coefficient values from the linear regressions by sub-fishery by $8.7 \%$ each year to have a total reduction of $87 \%$ (compared to the initial year) after a period of 10 years. 
3.3 Application of the CVA framework

We applied the viability framework described in section 2 to the NPF. In this study, the biological objective consists of ensuring that the prawn spawning stock size index $\mathrm{S}_{s}(y(t))$ of each individual species $s=1,2$ and 3 is maintained above a threshold value as:

$$
\mathrm{S}_{s}(y(t)) \geq \mathrm{S}_{s}^{\min }, \quad s=1,2,3 .
$$

with $S_{s}^{\min }$ the minimum spawning stock size index of species $s$ to maintain at each time.

NPF fishing management is assumed to be input based, and is represented in the model by setting the number of vessels to operate in a given year. The control $\mathrm{u}(t)$ corresponds here to the annual number of vessels $\mathrm{K}$. The NPF is a limited entry fishery, therefore changes in the maximum fleet size are not actually allowed. The work presented here is thus an artificial case study to assess effects of potential changes in fleet size. The biological viability probability (PVA) of the system, regarding $\mathrm{K}$, is then assessed by:

$$
\operatorname{PVA}(\mathrm{K})=\mathbb{P}\left(\text { constraints }(8) \text { are satisfied for } y(t)=y_{0}, \ldots, T\right) \text {. }
$$

The economic objective in this study requires maintaining a minimum total annual profit for the NPF such that:

$$
\pi(y(t)) \geq \pi^{\min }
$$

with $\pi^{\min }$ the minimal total annual profit to guarantee each year.

The economic viability probability of the fishery (EVA) is expressed as:

$$
\operatorname{EVA}(\mathrm{K})=\mathbb{P}\left(\text { constraint }(10) \text { are satisfied for } y(t)=y_{0}, \ldots, T\right) \text {. }
$$

The sea snake conservation objective considered in this study requires maintaining the catch of sea snakes below or equal to a maximum 'allowed' level:

$$
\mathrm{C}_{\text {snake }}(y(t)) \leq C_{\text {snake }}^{\max }
$$

with $C_{\text {snake }}^{\max }$ the maximum allowed total (i.e. by tiger and banana prawn sub-fisheries) catch of sea snakes.

The sea snake conservation or impact viability probability (IVA) of the NPF is then described by:

$$
\operatorname{IVA}(\mathrm{K})=\mathbb{P}\left(\text { constraint }(12) \text { are satisfied for } y(t)=y_{0}, \ldots, T\right) \text {. }
$$

The probability of co-viability (CVA) of the system, requiring that the biological, economic and sea snake conservation constraints are jointly considered in a stochastic context, is then given by:

$$
\mathrm{CVA}(\mathrm{K})=\mathbb{P}\left(\text { constraints }(8),(10) \text { and }(12) \text { are satisfied for } y(t)=y_{0}, \ldots, T\right) \text {. }
$$

The questions of where to set objective thresholds and which confidence level to choose remain crucial issues in viability analyses [55]. For instance, a lower threshold would lead to some trajectories being viable when they would not have been with a higher threshold. In this context, sensitivity analyses on the viability thresholds have been carried out in this study. 
3.4 Management strategies and scenarios

\subsubsection{Management strategies}

Three management strategies, which differ in their particular management objectives, are analysed. The NPF operates over two 'seasons' spanning the period April to November with a mid-season closure of variable length from June to August. Seasonal closures are in place to protect small prawns (closure from December to March), as well as spawning individuals (mid-season closure) [3]. Since annual efforts by vessel are strongly controlled by these seasonal closures, management strategies are here based on the fleet size, i.e. the number of vessels. A status quo management strategy SQ consists of setting the number of vessels to the current level, which corresponds to $\mathrm{K}^{\mathrm{SQ}}=52$ vessels. An economic management strategy $\max \mathrm{NPV}$ is examined, where the number of vessel $\mathrm{K}^{\max \mathrm{NPV}}$ is identified such as to maximize the average (given the stochastic nature of the model; i.e. uncertainties in tiger and blue endeavour prawn recruitments, white banana prawn annual biomasses and annual sea snake catches) net present value (NPV) of the whole fishery:

$$
\operatorname{NPV}\left(\mathrm{K}^{\max \mathrm{NPV}}\right)=\max _{\mathrm{K}} \mathbb{E}_{\omega(.)}[\mathrm{NPV}(\mathrm{K})] .
$$

Finally, a max CV management strategy is defined such that it seeks to guarantee the conservation of tiger and blue endeavour prawn stocks, to maintain the economic viability of the whole fishery and to reduce the impacts of trawling on sea snakes for all time periods of the simulation. The associated number of vessels $\mathrm{K}^{\max \mathrm{cv}}$ is thus identified so as to maximize the co-viability probability of the system:

$$
\operatorname{CVA}\left(\mathrm{K}^{\max \mathrm{cv}}\right)=\max _{\mathrm{K}} \operatorname{CVA}(\mathrm{K}) \text {. }
$$

\subsubsection{Scenarios}

Since tiger and banana prawn sub-fisheries have different levels of impacts on target species and by-catches, the biological, economic and sea snake conservation performances of the different management strategies are examined under three ${ }^{3}$ scenarios representing different effort combinations. The effort combinations differ in terms of the proportion of total annual effort allocated to the tiger prawn sub-fishery and are summarized in table 2 . The annual proportion $\propto_{1+2}(y(t))$ of effort directed towards the tiger prawn sub-fishery $(f=1+2)$ is expressed as in equation

$$
\left\{\begin{array}{l}
\mathrm{E}^{\mathrm{y}}(y(t))=\mathrm{E}_{f=1+2}^{\mathrm{y}}(y(t))+\mathrm{E}_{f=3}^{\mathrm{y}}(y(t)), \\
\propto_{1+2}(y(t))=\frac{\mathrm{E}_{f=1+2}^{\mathrm{y}}(y(t))}{\mathrm{E}^{\mathrm{y}}(y(t))}
\end{array}\right.
$$

where $\mathrm{E}^{\mathrm{y}}(y(t))$ is the total annual fishing effort for the entire NPF, and $\mathrm{E}_{f=1+2}^{\mathrm{y}}(y(t))$ and $\mathrm{E}_{f=3}^{\mathrm{y}}(y(t))$ correspond, respectively, to the annual effort of tiger prawn and banana prawn sub-fisheries during the year $y(t)$.

In two of the effort combinations, the annual proportion $\propto_{1+2}(y(t))$ of total effort allocated to tiger prawns is pre-defined. A 'balanced' effort combination $\left(\mathrm{T}_{50}\right)$ consists of allocating the total annual effort equally between the two sub-fisheries. A 'tiger' effort combination $\left(\mathrm{T}_{90}\right)$ is also analysed and involves allocating $90 \%$ of the annual

\footnotetext{
3 A number of intermediate combinations were also analysed, however, for the sake of simplicity, only three are displayed in this paper. The selected strategies presented here were of particular interest in the analysis carried out by Gourguet et al [32].
} 
effort to the tiger prawn sub-fishery. Finally, an 'adaptive' effort combination $\left(\mathrm{T}_{\text {adapt }}\right)$, which reflects current fishing behaviour in the NPF, is studied. Under this combination, the allocation of the total annual fishing effort between tiger and banana prawn fishing depends directly on white banana prawn catch per unit effort $\mathrm{CPUE}_{s=4}$ as described in Gourguet et al [32]. The resulting proportion of total annual effort directed to the tiger prawn sub-fishery under the 'adaptive' effort combination scenario ranges between 60 and $76 \%$.

Table 2 Effort combination scenarios (in each row) considered in this study. The combinations differ in the annual effort $\mathrm{E}_{1+2}(y(t))$ allocated to the tiger prawn sub-fishery $(f=1+2)$. $\mathrm{E}(y(t))$ stands for the total annual effort for the entire fishery

\begin{tabular}{lll}
\hline Effort combination & Description & Tiger prawn sub-fishery annual effort \\
\hline $\mathrm{T}_{50}$ & balanced effort combination & $\mathrm{E}_{1+2}(y(t))=0.5 \mathrm{E}(y(t))$ \\
$\mathrm{T}_{\text {adapt }}$ & adaptive effort combination (see Gourguet et al [32]) & $0.6 \mathrm{E}(y(t))<\mathrm{E}_{1+2}(y(t))<0.76 \mathrm{E}(y(t))$ \\
$\mathrm{T}_{90}$ & tiger effort combination & $\mathrm{E}_{1+2}(y(t))=0.9 \mathrm{E}(y(t))$ \\
\hline
\end{tabular}

For each of the three effort combination scenarios, the annual tiger prawn effort is then allocated by week and between grooved $(f=1)$ and brown $(f=2)$ fishing strategies as described in Gourguet et al [32].

\subsection{Cost of co-viability calculation}

We define the 'cost of co-viability' ( $\mathrm{c}_{\text {coviab }}$ ), corresponding to the opportunity cost of increasing the co-viability probability of the fishery, as the difference between the maximal average NPV (obtained under the management strategy $\max$ NPV) and the average NPV obtained with the $\max$ CV management strategy:

$$
\mathrm{c}_{\text {coviab }}=\operatorname{NPV}\left(\mathrm{K}^{\max \mathrm{NPV}}\right)-\mathrm{NPV}\left(\mathrm{K}^{\max \mathrm{cv}}\right)
$$

The marginal cost $(\Delta c)$ in terms of loss of NPV, and marginal gain in terms of CVA ( $\triangle \mathrm{CVA})$ of removing one vessel from a fleet of size $\mathrm{K}$ are then calculated as:

$$
\left\{\begin{array}{l}
\Delta c(\mathrm{~K})=\mathrm{NPV}(\mathrm{K})-\mathrm{NPV}(\mathrm{K}-1), \\
\Delta \mathrm{CVA}(\mathrm{K})=\mathrm{CVA}(\mathrm{K}-1)-\mathrm{CVA}(\mathrm{K}) .
\end{array}\right.
$$

\subsection{Numerical simulation approach}

1000 trajectories of spawning stock size indices and annual total profits are simulated over a 10 year period from 2010. Furthermore, to account for the uncertainty in the estimation of sea snake catches, for each of these 1000 trajectories, 10 estimations of sea snake catches are made as described in equation (6). Each trajectory represents a possible state of nature for each year of the simulation, $\left.\omega()=.\left(\omega_{1}(.), \omega_{2}(.), \omega_{3}(.), \omega_{4}(.), \omega_{5}^{i}(.)\right)_{i=1: 10}\right)$; which stands for the set of annual recruitments of tiger (grooved and brown) and blue endeavour prawn as detailed in Punt et al $[49,50]$, of white banana prawn annual biomasses as in appendix A.2, and of total annual sea snake catches as in equation (5). The different $\omega_{i}$ (.) are assumed to be independent by species. All combinations of scenarios (i.e. effort combination) and management strategies are simulated with the same set of $\omega($.$) .$ 
The numerical implementations and computations of the model were carried out with the scientific software SCILAB $^{4}$.

\section{Results}

The probabilities that biological, economic and sea snake conservation constraints will be met, separately and altogether (PVA, EVA, IVA and CVA), as well as the overall economic performance of the fishery (represented by the mean net present value, NPV) are presented below for each of the three management strategies (SQ, max NPV and $\max \mathrm{CV}$ ) under each of the three effort combination scenarios $\left(\mathrm{T}_{50}, \mathrm{~T}_{\text {adapt }}\right.$ and $\left.\mathrm{T}_{90}\right)$ described in section 3.4. The effort combination qualitatively closest to the current state of the NPF corresponds to a fleet with a size equal to that of a SQ management strategy (i.e. of 52 vessels) under an 'adaptive' effort combination ( $\mathrm{T}_{\text {adapt }}$ ). Viability probabilities and mean NPV results are described below as: $\mathrm{CVA}\left(\mathrm{K}^{\text {strategy }}\right.$, scenario $)$ and $\mathrm{NPV}\left(\mathrm{K}^{\text {strategy }}\right.$, scenario $)$.

4.1 Sensitivity of co-viability probability performance to threshold values

Sensitivity analyses on viability threshold values were carried out. Three different levels of the biological viability thresholds $S_{s}^{\min }$ (with $s=1,2,3$ ) were tested: a limit spawning stock size index $S_{s}^{\lim }$ corresponding to the minimal historically observed spawning stock size index value of species $s$ over the 1970-2010 period; a so-called 'spawning stock size index of precaution' $S_{s}^{\text {pa }}$ set by adjusting $S_{s}^{\lim }$ using a multiplier equal to 1.39: $S^{\text {pa }}=1.39 S^{\lim }$, as in ICES [38] and Bertignac and De Pontual [9]; and values of spawning stock size indices equal to $50 \%$ of the initial indices by species, i.e. $50 \%$ of their 2010 levels, also based on a precautionary approach [27]. Values are given in table 5 in appendix B. We varied the economic viability threshold value between 0 and the annual profit estimated in 2010 (i.e. AU\$ 11.9 millions [30]). Finally, the sea snake conservation viability threshold varied between the observed value of sea snake total catch by the NPF during the reference year (here 2010), i.e. 7,362 individuals and the maximal historically observed value since 2004, which corresponds to 13,045 individuals.

Figure 1 shows that the performance in terms of co-viability probability (CVA) of the fishery with a fleet size equal to that of a status quo (SQ) management strategy under an 'adaptive' effort combination scenario $\left(\mathrm{T}_{\text {adapt }}\right)$ is not very sensitive to the level of the biological viability thresholds. Hereafter, the biological viability thresholds are set to $50 \%$ of the 2010 spawning stock size indices, based on a precautionary approach [27]. The figure, however, shows that results are sensitive to the economic and sea snake conservation constraints. Therefore, results reported in the following sections should be interpreted with caution and in relation to the economic and sea snake conservation thresholds chosen hereafter. Following the definition of the biological threshold, the value of the economic threshold is set to $50 \%$ of the 2010 annual profit, which corresponds to AU\$ 5.95 million. Figure 1 shows that for a sea snake conservation viability threshold less than 8,500 individuals the probability of co-viability will be less than $50 \%$. Hereafter, the threshold for sea snake conservation constraint is defined as 11,000 individuals,

\footnotetext{
4 scILAB is a freeware http://www.scilab.org/ dedicated to engineering and scientific calculus. It is especially well-suited to deal with dynamic systems and control theory.
} 


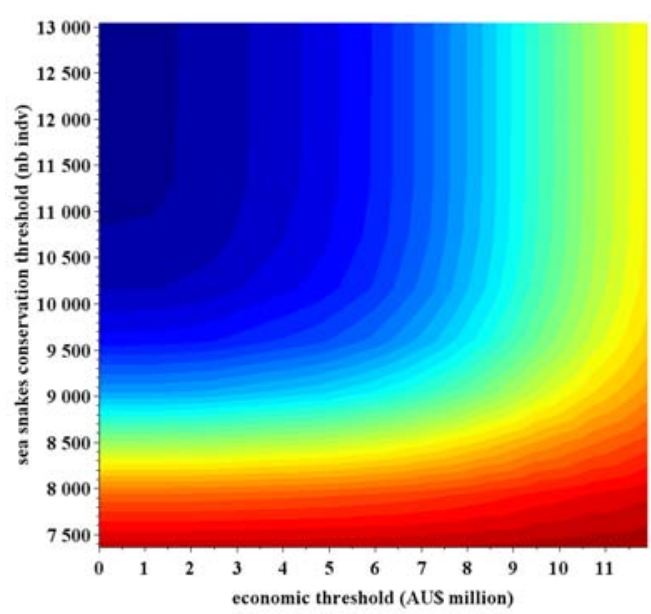

(a) Biological viability thresholds equal to $S_{s}^{\lim }$

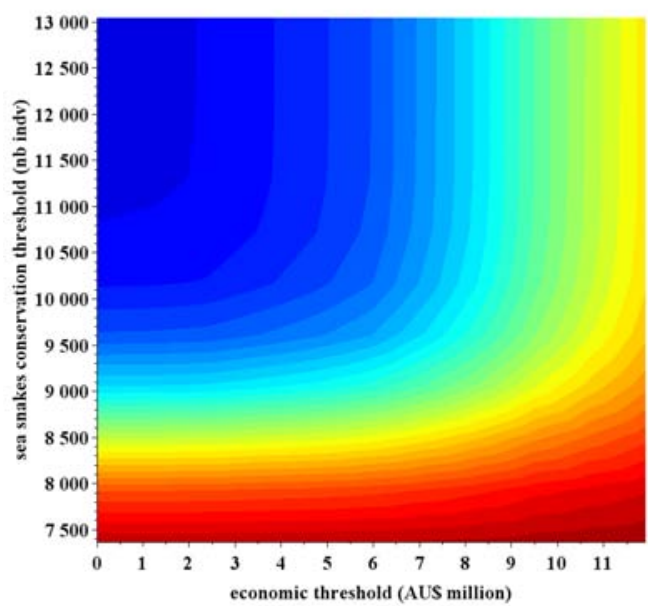

(c) Biological viability thresholds equal to $0.5 \mathrm{~S}_{s}(2010)$

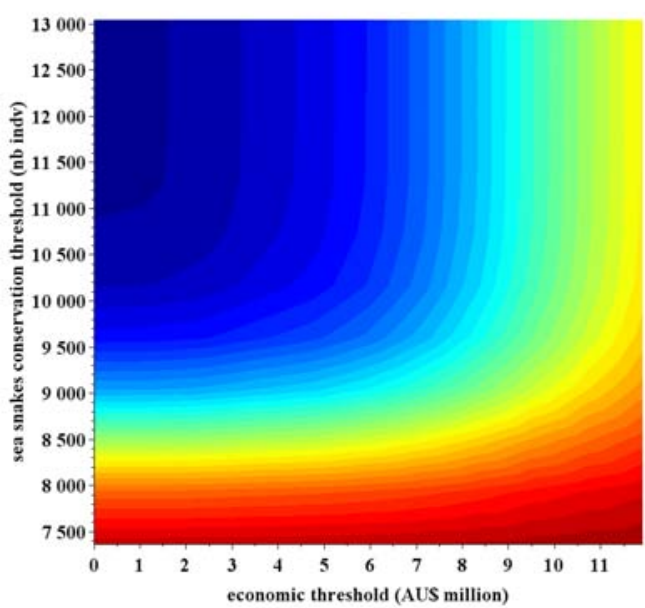

(b) Biological viability thresholds equal to $S_{s}^{\text {pa }}$

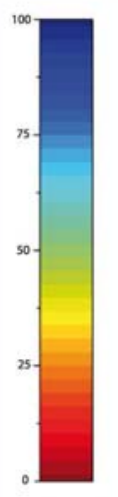

(d) Legend (CVA in \%)

Fig. 1 Co-viability probabilities (CVA) of the fishery (in percentage) with a fleet size equal to 52 vessels (i.e. SQ management strategy) under an 'adaptive' effort combination scenario $\left(\mathrm{T}_{\text {adapt }}\right)$ as functions of economic viability threshold levels ( $\mathrm{x}$ axis) and sea snake conservation viability threshold levels (y axis); with biological viability thresholds equal to limit spawning stock size indices $\left(S_{s}^{\lim }\right)$ in (a), to spawning stock size indices of precaution $\left(\mathrm{S}_{s}^{\mathrm{pa}}\right)$ in (b), and to $50 \%$ of the 2010 spawning stock size indices $\left(\mathrm{S}_{s}(2010) * 0.5\right)$ in (c). Legend for co-viability probability levels is displayed in (d)

which is slightly less than the maximum value of sea snake total catch calculated for the level of fishing effort associated with a status quo management strategy. Defining the sea snake conservation viability threshold in this way acknowledges the current MSC certification of the fishery, while recognizing a desire to improve ecological performance.

Values for the biological, economic and sea snake conservation viability thresholds used in the following sections are summarized table 6 in appendix B. 


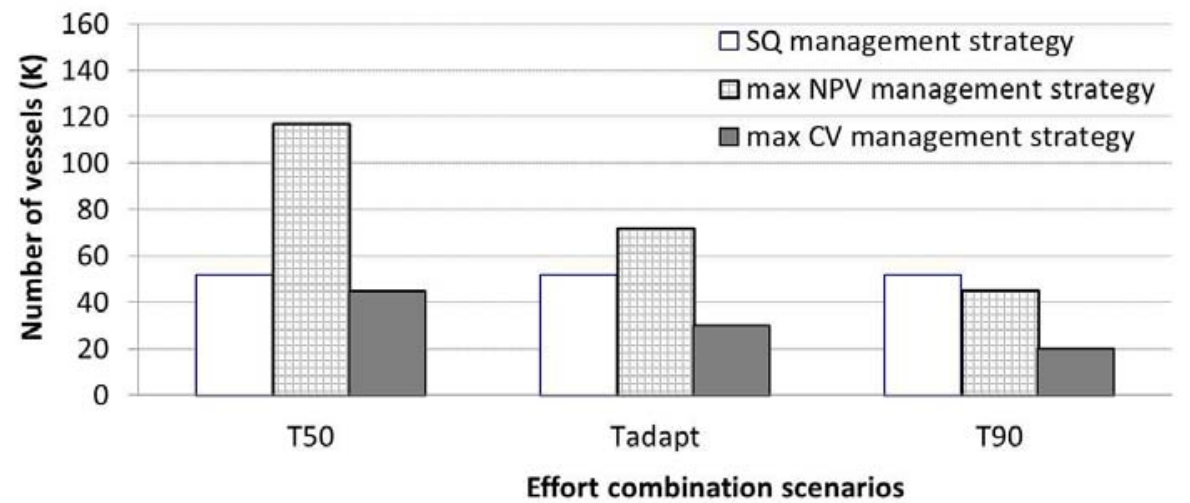

Fig. 2 Fleet sizes by management strategy: status quo (SQ), maximizing the co-viability probability ( $\max \mathrm{CV})$, and maximizing the net present value ( $\max \mathrm{NPV}$ ) under the three effort combination scenarios: $\mathrm{T}_{50}, \mathrm{~T}_{\text {adapt }}$ and $\mathrm{T}_{90}(\mathrm{x}$ axis)

Figure 2 shows that under each effort combination, the number of vessels that maximizes NPV (i.e. with the $\max$ NPV management strategy) is strictly higher than the number required to maximize CVA (i.e. with the $\max \mathrm{CV}$ management strategy). Furthermore fleet size under a $\max \mathrm{CV}$ management strategy is smaller than the 52 vessels associated with the status quo strategy, regardless of the effort combination scenario. Figure 2 exhibits also that the greater the annual proportion of tiger prawn sub-fishery effort, the smaller the fleet size obtained with the max NPV and $\max \mathrm{CV}$ management strategies. Moreover the difference between these two management strategies, in terms of number of vessels, is reduced when the proportion of tiger prawn sub-fishery effort increases.

4.3 Management strategy performances

Table 3 Biological (PVA), economic (EVA), sea snake conservation (IVA) and co-viability (CVA) probabilities and the associated mean net present value (NPV) of the three management strategies (i.e. status quo (SQ), maximizing the NPV (max NPV) and maximizing the CVA $(\max \mathrm{CV})$ ) under the different effort combination scenarios $\mathrm{T}_{50}, \mathrm{~T}_{\text {adapt }}$ and $\mathrm{T}_{90}$. Standard deviations of the NPV are displayed in parenthesis. Means and standard deviations are expressed in AU\$ million

\begin{tabular}{|c|c|c|c|c|c|c|c|}
\hline \multirow[b]{2}{*}{$\begin{array}{c}\text { Effort } \\
\text { combination }\end{array}$} & \multirow[b]{2}{*}{$\begin{array}{c}\text { Management } \\
\text { strategy }\end{array}$} & \multirow{2}{*}{$\begin{array}{c}\begin{array}{c}\text { Number } \\
\text { of vessels }\end{array} \\
\mathrm{K}\end{array}$} & \multicolumn{4}{|c|}{ Viability probability (in \%) } & \multirow[b]{2}{*}{$\begin{array}{c}\text { NPV } \\
\text { (in AU\$ million) }\end{array}$} \\
\hline & & & PVA & EVA & IVA & CVA & \\
\hline \multirow{3}{*}{$\mathrm{T}_{50}$} & SQ & 52 & 94.6 & 47.2 & 100 & 45.4 & $434(151)$ \\
\hline & $\max \mathrm{NPV}$ & 117 & 67.3 & 13 & 0 & 0 & $\mathbf{5 8 1 . 4 1}(331.94)$ \\
\hline & $\max \mathrm{CV}$ & 45 & 95.9 & 48.5 & 100 & 47.1 & $396.14(131.1)$ \\
\hline \multirow{3}{*}{$\mathrm{T}_{\text {adapt }}$} & SQ & 52 & 90.5 & 86.6 & 99.5 & 80.51 & $429.26(116.74)$ \\
\hline & $\max$ NPV & 72 & 77.1 & 61 & 21.5 & 12.03 & $455.27(163.01)$ \\
\hline & $\max \mathrm{CV}$ & 30 & 96.3 & 93.8 & 100 & 91.2 & $324.17(66.69)$ \\
\hline \multirow{3}{*}{$\mathrm{T}_{90}$} & SQ & 52 & 77.4 & 83.4 & 93.5 & 65.7 & $337.81(93.26)$ \\
\hline & $\max$ NPV & 45 & 84.6 & 91.8 & 99.6 & 79.93 & $343.37(83.34)$ \\
\hline & $\max \mathrm{CV}$ & 20 & 96.7 & 96.8 & 100 & 94.2 & $248.76(41.73)$ \\
\hline
\end{tabular}


Results (table 3) demonstrate that status quo management strategies do not achieve the highest mean NPV, as calculated in this study. As found in other studies, e.g. Pascoe et al [46], the current limit on vessel numbers prevents indeed NPV from being maximised. Management has been focused on the tiger prawn component of the fishery and has not previously taken into account the effects of the banana prawn component on optimal fleet size. Furthermore, as was shown in Gourguet et al [32], while aimed at maximizing the NPV of the fishery, current management also seems to seek limited variability in economic performance. Table 3 shows that the biological, economic and sea snake conservation constraints are met with varying probabilities according to management strategies and effort combination scenarios. Results suggest that, under the modeling assumptions used, current management of the fishery (i.e. $\mathrm{T}_{\text {adapt }}$ effort combination with 52 vessels) may have a moderate viability (coviability probability (CVA) equal to $80.51 \%$ ). This is because this management strategy has moderate biological and economic risks (biological (PVA) and economic (EVA) viability probabilities equal to $90.5 \%$ and $86.6 \%$, respectively). Table 3 shows that for max CV management strategies, which involve a reduced number of vessels, there is a $100 \%$ probability of operating within the sea snake conservation constraint (IVA). Moreover, there exist management strategies involving high biological, economic and sea snake conservation viability probabilities. The highest CVA would be obtained with a $\mathrm{T}_{90}$ effort combination and a reduction of the fleet size to 20 vessels: $\operatorname{CVA}\left(20, \mathrm{~T}_{90}\right)=94.2 \%$. The highest mean NPV is obtained in our simulations with a $\mathrm{T}_{50}$ effort combination and an increase in the size of the fleet to 117 vessels. However, this strategy would not be ecologically viable (with a zero probability of not exceeding the allowed level of sea snake catch for all years of the simulation) and would be associated with low probabilities of not violating biological and economic thresholds.

\subsection{Trade-offs and cost of co-viability}

Figure 3 represents the trade-off between the mean annual profit and the average annual by-catch of sea snakes (for the entire fishery) for the different management strategies and effort combination scenarios. Points to the NorthWest of the graph correspond to greater mean annual profits and reduced by-catch. The status quo management strategy under an 'adaptive' effort combination scenario, i.e. the closest to that currently implemented, appears to represent a compromise between economic performance and the level of by-catch. While the best mean economic performance is achieved with a $\mathrm{T}_{50}$ effort combination under a max NPV management strategy (related to an increase of the fleet size), this is associated with high variability of the annual profit and a high level of sea snake by-catch. In contrast, max $\mathrm{CV}$ management strategies under $\mathrm{T}_{\text {adapt }}$ and $\mathrm{T}_{90}$ effort combinations, which are associated with a decrease in fleet size, induce the lowest levels of economic variability and by-catch.

By definition, under each effort combination scenario, $\max \mathrm{CV}$ management strategies perform best in terms of co-viability probability (table 3). However, these entail an economic loss which can be interpreted as a 'cost of co-viability' associated with the objective to simultaneously meet all the constraints imposed on the fishery, i.e. the opportunity cost of increasing CVA (c.f. table 4). It is worth noting that, under each effort combination, the loss associated with achieving co-viability is higher than the loss associated with the status quo management strategy. 


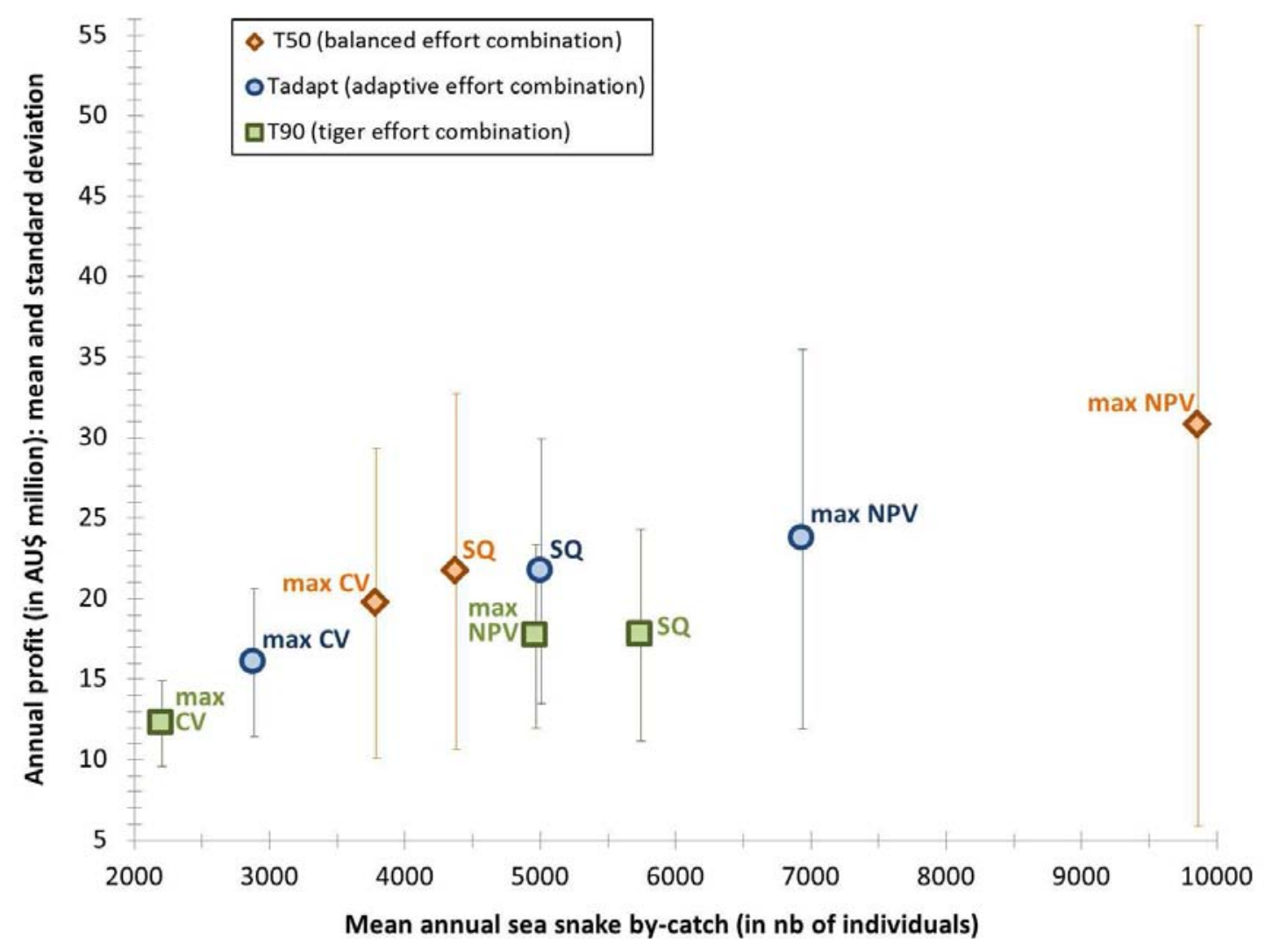

Fig. 3 Performances, in terms of annual profit (mean and standard deviation) versus average annual by-catch of sea snakes, of the different management strategies (i.e. status quo (SQ), maximizing the co-viability probability ( $\max \mathrm{CV}$ ), and maximizing the net present value (max NPV)) under the three effort combination scenarios $\left(\mathrm{T}_{50}, \mathrm{~T}_{\text {adapt }}\right.$ and $\left.\mathrm{T}_{90}\right)$

Table 4 Cost of co-viability (in terms of total value and of percentage of maximum net present value (NPV) achievable given an effort combination scenario) and associated gain of co-viability probability (CVA) according to the three effort combination scenarios

\begin{tabular}{|c|c|c|c|}
\hline \multirow[b]{2}{*}{$\begin{array}{l}\text { Effort combination } \\
\text { scenario }\end{array}$} & \multicolumn{2}{|c|}{ Total cost of co-viability } & \multirow[b]{2}{*}{$\begin{array}{c}\text { Total gain of CVA } \\
\text { in } \%\end{array}$} \\
\hline & $\begin{array}{c}\text { Value } \\
\text { in AU\$ million }\end{array}$ & $\begin{array}{c}\% \text { of the highest NPV achievable } \\
\text { according to effort combination } \\
\text { in } \%\end{array}$ & \\
\hline $\mathrm{T}_{50}$ & 185.27 & 31.86 & 47.1 \\
\hline $\mathrm{T}_{\text {adapt }}$ & 131.1 & 28.8 & 79.17 \\
\hline $\mathrm{T}_{90}$ & 94.61 & 27.55 & 14.27 \\
\hline
\end{tabular}

\footnotetext{
5 As the fleet size of the NPF has historically been reduced, this study assesses the marginal cost of removing vessels instead of the marginal effects of increasing the fleet.
} 


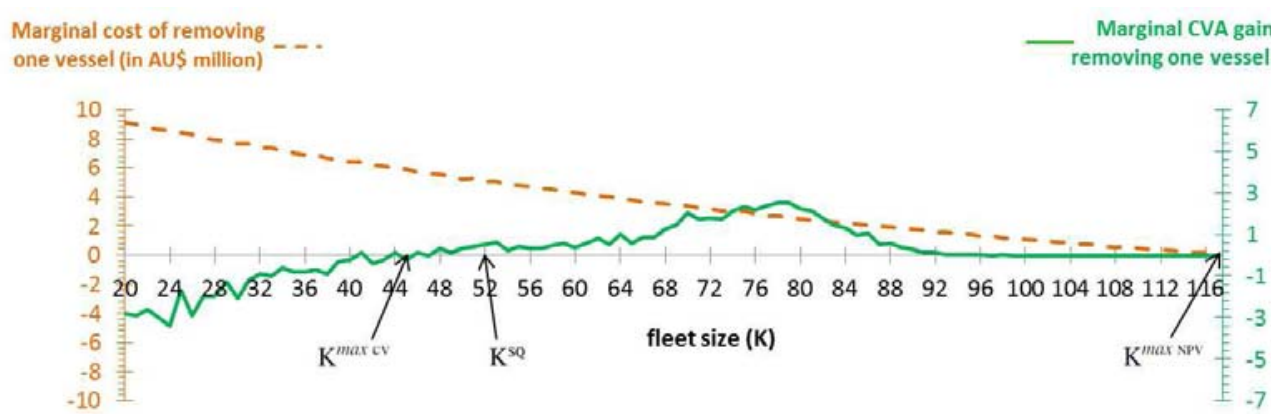

(a) $\mathrm{T}_{50}$ effort combination scenario

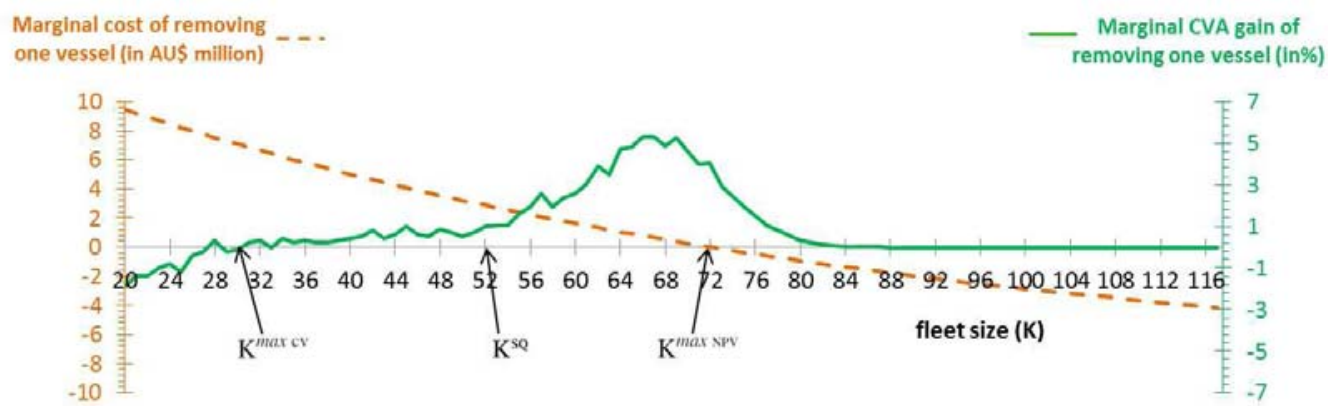

(b) $T_{\text {adapt }}$ effort combination scenario

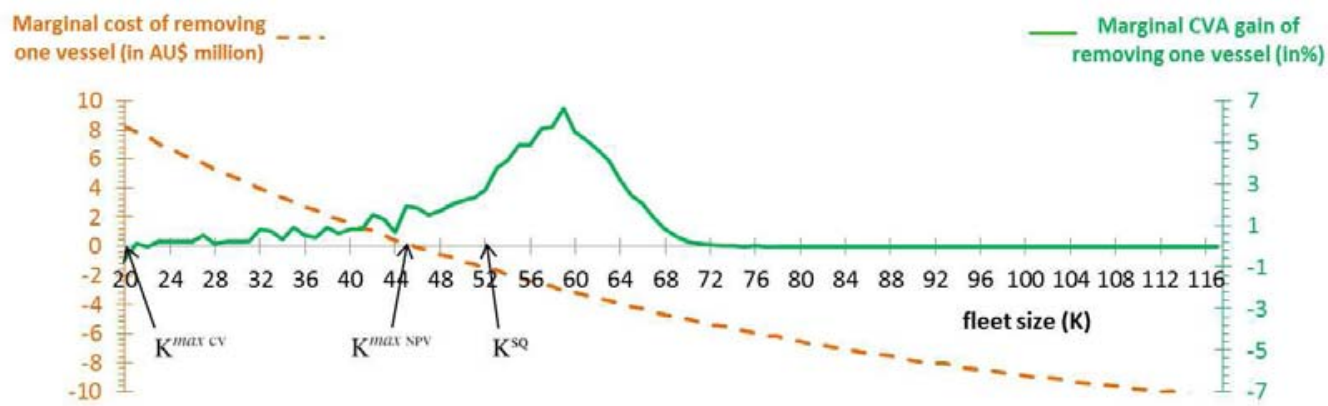

(c) $\mathrm{T}_{90}$ effort combination scenario

Fig. 4 Marginal cost (in AU\$ million; dotted line) and marginal gain of co-viability probability (CVA) (in \%; plain line) of removing one vessel as functions of the fleet size ranging from 20 to 117 vessels; with $\mathrm{T}_{50}$ effort combination scenario in (a), $\mathrm{T}_{\text {adapt }}$ effort combination scenario in (b), and $\mathrm{T}_{90}$ effort combination scenario in (c). For each effort combination scenario, $\mathrm{K}^{\mathrm{se}}, \mathrm{K}^{\max \mathrm{cv}}$ and $\mathrm{K}^{\max \mathrm{NPV}^{\mathrm{NV}}}$ stand for the number of vessels associated with a status quo management strategy, with a strategy of maximizing the co-viability probability and with a strategy of maximizing the net present value of the fishery, respectively

In contrast, the marginal gain of CVA (of removing one vessel from the fleet) increases initially as the fleet size increases, but then the marginal gain of CVA is decreasing. Starting from a large fleet size, removing successive vessels seems to have little effect on the probability of co-viability, as high vessel numbers continue to make viability constraints unattainable. As further vessels are removed, the effects are more marked with a marginal gain of co-viability increasing to reach a maximum. Further reductions will however result in a decline in marginal co-viability gain with it eventually becoming negative. For example, in the case of $\mathrm{T}_{50}$, marginal reductions in fleet 

size below 45 vessels (i.e. $\mathrm{K}^{\operatorname{maxcv}}$ ) reduce the probability of achieving co-viability as the fishery fails to meet the economic viability constraint. While $\mathrm{T}_{50}$ and $\mathrm{T}_{\text {adapt }}$ have the highest total gains of co-viability (table 4 ) compared to that with the tiger specialization effort combination $\left(\mathrm{T}_{90}\right)$, the highest marginal gain of CVA is found for $\mathrm{T}_{90}$ (figure 4).

\section{Discussion and conclusions}

The model used here accounts for the interactions between tiger and banana prawn sub-fisheries within a simplified model of the Northern Prawn Fishery (NPF). It allows us to assess the ability of fishing management strategies to meet multiple constraints imposed on the fishery. Management strategies differ in the number of vessels ${ }^{6}$ involved across the fishery, and are evaluated under different effort combination scenarios describing the proportion of effort allocated to the tiger prawn sub-fishery. Their performance is mainly evaluated in terms of co-viability probability (CVA) and average net present value (NPV). The co-viability probability measures the capacity of the fishery to respect constraints related to the objectives of preserving target stocks, maintaining acceptable levels of annual profit, and reducing the impacts of the fishery on non-target species such as sea snakes. Results illustrate the inevitable trade-offs which exist in managing exploited marine ecosystems [14]. Respecting certain constraints may entail a cost in terms of losses in expected economic return. This is what we propose to call the "cost of co-viability'.

5.1 Assessment of the co-viability of the fishery

This work differs from previous studies of the NPF [18, 19, 49], as in our study the banana prawn sub-fishery is explicitly integrated in the bio-economic model and the economic management strategy is exclusively based on the maximization of mean net present value of profits. Furthermore, interactions between trawlers and nontarget sea snakes are explicitly modeled in this study through sea snake catches. Results exhibit that the status quo management strategy is not achieving the maximum NPV. In Gourguet et al [32], this strategy is shown to reflect the objective of balancing average economic performance versus performance variability in the fishery. While, the current management strategy appears to be constrained by the fleet size, which is more conservative than that which may maximise NPV (i.e. max NPV management strategy), this smaller fleet size is not enough to meet the biological and economic inter-annual equity constraints. Indeed, if the objective is to improve management of biological and economic risks, our results indicate the need for further reductions in the fleet size. More specifically, our analysis shows that, under the 'adaptive' ( $\mathrm{T}_{\text {adapt }}$, where the proportion of effort directed towards tiger prawn sub-fishery is comprised between 60 and $76 \%$ of total effort) or the 'balanced' ( $\mathrm{T}_{50}$ which allocates the total annual effort equally between the tiger and banana prawn sub-fisheries) effort combination scenarios, management strategies aimed at maximizing the CVA lead to proposed reductions in fleet size, whereas management strategies aimed at

${ }^{6}$ The NPF is a limited entry fishery and changes in the maximum fleet size are not allowed. The work presented here is thus an artificial case study to assess effects of potential changes in fleet size. 
maximizing the NPV are related to increases in fleet size, as compared to the status quo. This is consistent with results from Gourguet et al [32] where higher mean NPV are associated with management settings involving larger fleet sizes and fishery effort directed more towards fishing banana prawns (the $\mathrm{T}_{50}$ effort combination achieving the highest economic yield in our study). However, results show that strategies which maximize the NPV under a $\mathrm{T}_{\text {adapt }}$ or a $\mathrm{T}_{50}$ effort combination scenarios are associated with a low probability of meeting the sea snake conservation objective, due to increases in sea snake catches. These strategies - allocating effort to the banana prawn sub-fishery and increasing the fleet size - are also associated with strongly reduced probabilities of viable economic performance due to an increase in the variability of profits, which leads to violation of the inter-annual equity objective. While the greater fishing capacity allows fishers to make the most of the peak abundance years in banana prawns, this is associated with a correspondingly high level of inter-annual variability in economic yield [32].

\subsection{Cost of co-viability}

As pointed out by Cheung and Sumaila [14], Mouysset et al [45] or Sainsbury et al [52] understanding the underlying trade-off among management objectives is important in designing policies to manage ecosystems, as it might for instance facilitate reaching agreement between stakeholders. A trade-off in fishery management performance between co-viability probabilities and mean NPV is observed and analysed in our study ${ }^{7}$. A similar trade-off between maintaining given levels of fish biomass and the net financial returns from fishing under different management regimes was also observed in Little et al [41]. Analyses presented in our paper highlight that higher co-viability probabilities can be achieved with management strategies aimed at maximizing the CVA, but only at the cost of forgoing mean economic yield in the fishery. This economic loss represents the cost of meeting all constraints imposed on the fishery. This 'cost of co-viability' is estimated as the difference between the mean NPV value obtained with the max NPV management strategy and that with the max CV management strategy. Based on the assumptions defined here, it appears that, under the current effort combination scenario $\mathrm{T}_{\text {adapt }}$, respecting all constraints considered in this study with the maximum probability achievable will have a cost of co-viability of AU\$ 131.1 million. This corresponds to $28.8 \%$ of the NPV value which would be obtained if the fishery were managed to maximize NPV under a similar effort combination $\mathrm{T}_{\text {adapt }}$. Management of the fishery might therefore require a balancing of the willingness of the fishing industry to accept changes that would reduce its biological and economic risks and its impacts on sea snakes, against acceptance of a reduction in potential economic yield. An important thing to note is that due to the fact that the status quo (SQ) management strategy is not achieving the maximum mean NPV, this estimate of the cost of co-viability may actually be an over-estimate of the loss fishers would experience by accepting management change aimed at improving ecological performance and avoiding economic risk. Compared to the SQ management strategy, the estimated loss would indeed be AU\$ 105.09

\footnotetext{
7 Comparison of results with and without discounting enabled us to dismiss the hypothesis that discounting is driving the trade-off between CVA and mean NPV.
} 
million (24.48\% of the NPV value which would be obtained with a SQ management strategy under a $\mathrm{T}_{\text {adapt }}$ effort combination scenario).

This study assesses the marginal costs and associated marginal gains in terms of CVA when improving the ecological performance of the fishery and reducing economic risk by reducing the fleet size. Results show that the marginal cost of removing one vessel decreases as the fleet size is increasing. It is thus more costly to remove one vessel from a small fleet than from a larger fleet. However, the associated marginal gain of co-viability probability is non-linear in fleet size. Indeed, marginal CVA gain increases as the fleet size increases up to 66 vessels (resp. 78 vessels and 59 vessels) when considering the $T_{\text {adapt }}$ effort combination scenario (resp. considering $T_{50}$ and $T_{90}$ effort combinations), after which the marginal gain of CVA decreases. In cases where consensus between stakeholders is difficult to reach, this sort of analysis could assist policy-makers and fisheries managers assessing the opportunity cost of meeting improved co-viability probabilities. For instance, considering the case $T_{\text {adapt }}$, which reflects the current situation in the NPF, our analysis shows that reduction of fleet size from 52 to 51 vessels will secure an increase in CVA of $1.01 \%$ (from $80.51 \%$ to $81.52 \%$ ) at a cost of AU $\$ 2.87$ million (i.e. a $0.67 \%$ reduction in mean $\mathrm{NPV}$ ), information that can help focus debate on the real trade-offs. Interestingly also, in the case of $\mathrm{T}_{90}$ effort combination scenario, reducing the fleet size from 52 to 51 should be non-contentious as it would result in a $2.74 \%$ increase in CVA and a $0.46 \%$ increase in NPV (marginal gain of NPV equal to AU\$ 1.57 million).

Analyses also show that overall, for a given fleet size, the greater the annual effort that is directed towards the banana prawn sub-fishery, the greater the marginal cost of removing one vessel. This might be explained by the fact that banana specialization effort combination scenarios are more advantageous when the fleet size is bigger, while tiger specialization effort combination scenarios are more favourable for smaller fleets [32].

\subsection{Integrated management of mixed fisheries and limits}

The consideration of the multi-dimensional nature of marine fisheries management is an unavoidable reality. As Dichmont et al [20] and Thébaud et al [55] pointed out, management strategies should indeed explicitly consider contested objectives from different stakeholders. The stochastic co-viability approach presented here formally recognizes the multi-objective nature of management for the NPF, and integrates this with the current understanding of the dynamics of a mixed fishery system. More specifically, this study proposes an analytical framework which allows quantifying the trade-offs between increasing the ecological performance of a fishery and maximizing its economic performance. As pointed out by Seijo and Caddy [53], indicators for fisheries performance are an integral part of fisheries management plans providing dynamic signs of the relative position of fishery performance with respect to predetermined reference points. However, the question of which reference points to choose remains a crucial issue, especially in contexts where environmental and economic uncertainties coexist. Sensitivity analysis results demonstrate that viability outcomes are more or less sensitive to the constraints and associated threshold values. Viability results must thus be interpreted with caution. The biological thresholds in this study are set to $50 \%$ of the assessed levels in 2010 (the reference year). These biological levels can actually be considered 
as precautionary reference points [12], rather than limit reference points. Maintaining the spawning stock sizes above these precautionary levels could be seen as a means of avoiding stock collapses, as long as the broader ecological conditions in which the stocks occur are maintained. Difficulties may exist with respect to setting the threshold for impacts on sea snakes, as no stock assessments have been carried to this date. Adaptations of the NPF fishery to reduce current levels of impacts of trawling on sea snakes are likely to depend on the extent to which operators in the fishery accept higher levels of risks. Viability results from this study are also sensitive to the economic threshold value. Results should therefore be interpreted in light of the selected thresholds. However, examination of the sensitivity of the comparison between the alternative management strategies to the definition of the thresholds showed that while results vary quantitatively, comparisons between management strategies do not change qualitatively. In practical management situations, identifying such thresholds would need to involve stakeholders, and the results of such sensitivity analysis could inform the process of deciding on adequate values to retain for a viability assessment, as has been shown by Thébaud et al [55]. The strong links between maximin and viability approaches pointed out in Doyen and Martinet [23] can also bring important insights in this respect.

As part of the consideration of the multi-dimensional nature of marine fisheries management, consideration of the environmental impacts of fishing activities is a crucial concern, as these impacts can lead to changes in biodiversity and ultimately change the overall functionality of the ecosystem [25, 47]. However, fishery scientists and managers often do not have the information required to properly assess fishery impacts on non-target species and communities, or to develop management measures to ensure that the fishery operates in an ecologically sustainable manner [58]. In such cases, use of a proxy for fishing impacts on non-target species as proposed in this study (through sea snake catches), can assist in explicitly addressing the impacts of fishing on non-target species in assessments. In the context of the NPF, the analysis could be extended to include a suite of groups (such as rays, sharks, sawfishes, turtles, etc.) in the definition of a biodiversity conservation objective imposed on managing the fishery. A further extension of this work could be to allow the number of vessels to change over time. However the dimension of the problem will then be very high, which would be very demanding in terms of computer time and estimation performance.

\subsection{Conclusions}

This paper addresses the need to understand trade-offs between various objectives in marine fisheries management given uncertainty in the potential responses to regulations. The model-based framework we propose is applied to the evaluation of alternative management strategies in the Australian Northern Prawn Fishery (NPF), with biological, economic and non-target species conservation objectives. We defined co-viability probability (CVA) as a measure of the likelihood of respecting constraints related to the preservation of target stocks, the maintenance of acceptable levels of annual profit, and the reduction of the impacts of the fishery on non-targeted sea snakes. Higher co-viability probabilities can be achieved with management strategies aimed at maximizing CVA, but only at the cost of forgoing economic yield in the fishery (which we call the 'cost of co-viability'). In particular, lim- 
iting biological and economic risks would require reductions in the fleet size compared to the status quo, which entails losses of expected economic return. Analysis of marginal costs and associated gains (in terms of CVA) also shows that, for a given fleet size, the greater the annual effort that is directed towards the banana prawn sub-fishery, the greater the marginal cost of fleet reduction. While viability probabilities must be interpreted with caution due to sensitivity to the constraints and associated threshold values, comparisons between management strategies do not change qualitatively when multiple threshold values are tested. The proposed framework can assist fisheries managers and stakeholders in seeking consensus when assessing management strategies. Promising future developments involve the incorporation of a broader set of objectives including social dimensions, as well as the integration of ecological interactions, to better address the needs of ecosystem-based approaches to the sustainable harvesting of marine biodiversity.

Acknowledgements This work was supported by the French Research Agency ANR through the project Adhoc, the Australian Fisheries Research and Development Corporation (FRDC), the University of Tasmania (UTAS)/ Commonwealth Scientific and Industrial Research Organisation (CSIRO) PhD Program in Quantitative Marine Science, and the French Research Institute for Exploitation of the Sea (Ifremer). We are grateful to the CSIRO researchers providing us with access to data and knowledge of the fishery, and especially to Rodrigo Bustamante and Rik Buckworth for helpful discussions on the model and the case study. We also thank two anonymous reviewers and the associate editor for their helpful comments on an earlier version of the manuscript.

\section{References}

1. ABARES (2010) Australian commodity statistics 2010. Tech. rep., Australian Bureau of Agricultural and Resource Economics, Canberra, Australia.

2. AFMA (2012) Ecological Risk Management: report for the Northern Prawn Fishery tiger and banana prawn sub-fisheries. Tech. rep., Australian Fisheries Management Authority, Canberra, Australia.

3. AFMA, CSIRO (2012) Harvest Strategy for the Northern Prawn Fishery under input controls. Tech. rep., Canberra

4. Alverson D, Freeberg M, Murawski S, Pope J (1994) A global assessment of fisheries bycatch and discards. FAO Fisheries Technical Paper 339:233

5. Aubin JP (1990) A survey of viability theory. SIAM Journal on Control and Optimization 28(4):749-788

6. Banks R, Clarke S, Staples D, Souter D (2012) Australia Northern Prawn Fishery: Public Comment Draft Report. MRAG Americas, Inc p 397

7. Baumgärtner S, Quaas MF (2009) Ecological-economic viability as a criterion of strong sustainability under uncertainty. Ecological Economics 68(7):2008-2020

8. Béné C, Doyen L, Gabay D (2001) A viability analysis for a bio-economic model. Ecological Economics 36(3):385-396

9. Bertignac M, De Pontual H (2007) Consequences of bias in age estimation on assessment of the northern stock of European hake (Merluccius merluccius) and on management advice. ICES Journal of Marine Science: Journal du Conseil 64(5):981-988

10. Brewer D, Heales D, Milton D, Dell Q, Fry G, Venables B, Jones P (2006) The impact of turtle excluder devices and bycatch reduction devices on diverse tropical marine communities in Australia's Northern prawn trawl fishery. Fisheries Research 81(2):176-188

11. Bustamante RH, Dichmont CM, Ellis N, Griffiths S, Rochester WA, Burford MA, Rothlisberg PC, Dell Q, Tonks M, Lozano-Montes H, Deng R, Wassenberg T, Okey TA, Revill A, van der Velde J, Moeseneder C, Cheers S, Donovan A, Salini T, Fry G, Tickell S, Pascual R, Smith F, Morello E, Taranto T (2010) Effects of trawling on the benthos and biodiversity: Development and delivery of a Spatially-explicit Management Framework for the Northern Prawn Fishery. Final report to the project FRDC 2005/050. Tech. rep., CSIRO Marine and Atmospheric Research, Cleveland

12. Caddy JF, Mahon R (1995) Reference points for fisheries management. FAO fisheries technical paper 347:83 
13. Charles AT (1989) Bio-socio-economic fishery models: labour dynamics and multi-objective management. Canadian journal of fisheries and aquatic sciences 46(8):1313-1322

14. Cheung WWL, Sumaila UR (2008) Trade-offs between conservation and socio-economic objectives in managing a tropical marine ecosystem. Ecological Economics 66(1):193-210

15. Crutchfield JA (1973) Economic and political objectives in fishery management. Transactions of the American Fisheries Society 102(2):481-491

16. De Lara M, Martinet V (2009) Multi-criteria dynamic decision under uncertainty: A stochastic viability analysis and an application to sustainable fishery management. Mathematical Biosciences 217(2):118-124

17. Dichmont CM, Punt AE, Deng AR, Dell Q, Venables W (2003) Application of a weekly delay-difference model to commercial catch and effort data for tiger prawns in Australia's Northern Prawn Fishery. Fisheries Research 65(1-3):335-350

18. Dichmont CM, Deng AR, Punt AE, Ellis N, Venables W, Kompas T, Ye Y, Zhou S, Bishop J (2008) Beyond biological performance measures in Management Strategy Evaluation: Bringing in economics and the effects of trawling on the benthos. Fisheries Research 94(3):238-250

19. Dichmont CM, Pascoe S, Kompas T, Punt AE, Deng AR (2010) On implementing maximum economic yield in commercial fisheries. Proceedings of the National Academy of Sciences 107(1):16-21

20. Dichmont CM, Ellis N, Bustamante RH, Deng AR, Tickell S, Pascual R, Lozano-Montes H, Griffiths S (2013) EDITOR'S CHOICE: Evaluating marine spatial closures with conflicting fisheries and conservation objectives. Journal of Applied Ecology 50(4):1060-1070

21. Die DJ, Ellis N (1999) Aggregation dynamics in penaeid fisheries: banana prawns (Penaeus merguiensis) in the Australian Northern Prawn Fishery. Marine and freshwater research 50(7):667-675

22. Doyen L, De Lara M (2010) Stochastic viability and dynamic programming. Systems $\mathcal{E}$ Control Letters 59(10):629-634

23. Doyen L, Martinet V (2012) Maximin, viability and sustainability. Journal of Economic Dynamics and Control 36(9):1414-1430

24. Doyen L, Thébaud O, Béné C, Martinet V, Gourguet S, Bertignac M, Fifas S, Blanchard F (2012) A stochastic viability approach to ecosystem-based fisheries management. Ecological Economics 75:32-42

25. Dulvy NK, Metcalfe JD, Glanville J, Pawson MG, Reynolds JD (2000) Fishery stability, local extinctions, and shifts in community structure in skates. Conservation Biology 14(1):283-293

26. Ellis N, Pantus F, Pitcher CR (2014) Scaling up experimental trawl impact results to fishery management scales - a modelling approach for a "hot time". Canadian Journal of Fisheries and Aquatic Sciences 71(5):733-746

27. FAO (1996) Precautionary approach to capture fisheries and species introduction. Tech. Rep. 2, FAO Technical Guidelines for Responsible Fisheries, Rome

28. Fry GC, Milton DA, Wassenberg T (2001) The reproductive biology and diet of sea snake bycatch of prawn trawling in Northern Australia: characteristics important for assessing the impacts on populations. Pacific conservation biology 7(1):55

29. Garcia SM, Kolding J, Rice J, Rochet MJ, Zhou S, Arimoto T, Beyer JE, Borges L, Bundy A, Dunn D, et al (2012) Reconsidering the consequences of selective fisheries. Science 335(6072):1045-1047

30. George D, Vieira S, R N (2012) Australian fisheries surveys report 2011, results for selected fisheries 2008-09 to 2010-2011. Tech. rep., Australian Bureau of Agricultural and Resource Economics and Sciences, Canberra, February

31. Gourguet S, Macher C, Doyen L, Thébaud O, Bertignac M, Guyader O (2013) Managing mixed fisheries for bio-economic viability. Fisheries Research 140:46-62

32. Gourguet S, Thébaud O, Dichmont CM, Jennings S, Little LR, Pascoe S, Deng RA, Doyen L (2014) Risk versus economic performance in a mixed fishery. Ecological Economics 99:110-120

33. Griffiths SP, Brewer DT, Heales DS, Milton DA, Stobutzki IC (2006) Validating ecological risk assessments for fisheries: assessing the impacts of turtle excluder devices on elasmobranch bycatch populations in an Australian trawl fishery. Marine and Freshwater Research 57(4):395-401

34. Griffiths SP, Kenyon R, Bulman C, Dowdney J, Williams A, Sporcic M, Fuller M (2007) Ecological Risk Assessment for the Effects of Fishing: Report for the Northern Prawn Fishery. Tech. rep., Report for the Australian Fisheries Management Authority, Canberra

35. Hall SJ, Mainprize BM (2005) Managing by-catch and discards: how much progress are we making and how can we do better? Fish and Fisheries 6(2):134-155

36. Haywood M, Hill B, Donovan A, Rochester W, Ellis N, Welna A, Gordon S, Cheers S, Forcey K, Mcleod I, Moeseneder C, Smith G, Manson F, Wassenberg T, Thomas S, Kuhnert P, Laslett G, Buridge C, Thomas S (2005) Quantifying the effects of trawling on seabed fauna in the Northern Prawn Fishery. Final Report on FRDC Project 2002/1020. Tech. rep., CSIRO Marine and Atmospheric Research, Cleveland

37. Hill BJ, Wassenberg TJ (2000) The probable fate of discards from prawn trawlers fishing near coral reefs: A study in the northern Great Barrier Reef, Australia. Fisheries Research 48(3):277-286 
38. ICES (2001) Report of the Study Group on the Further Development of the Precautionary Approach to Fishery Management. Tech. rep., ICES Document CM 2001/ACFM: 11.

39. Kelleher K (2005) Discards in the world's marine fisheries: an update. FAO fisheries technical paper 470

40. Kompas T, Dichmont CM, Punt AE, Deng A, Che TN, Bishop J, Gooday P, Ye Y, Zhou S (2010) Maximizing profits and conserving stocks in the Australian Northern Prawn Fishery. Australian Journal of Agricultural and Resource Economics 54(3):281-299

41. Little LR, Grafton RQ, Kompas T, Smith ADM, Punt AE, Mapstone BD (2011) Complementarity of No-Take Marine Reserves and Individual Transferable Catch Quotas for Managing the Line Fishery of the Great Barrier Reef. Conservation Biology 25(2):333-340

42. Martinet V, Thébaud O, Rapaport A (2010) Hare or tortoise? trade-offs in recovering sustainable bioeconomic systems. Environmental Modeling and Assessment 15(6):503-517

43. Milton DA, Zhou S, Fry GC, Dell Q (2008) Risk assessment and mitigation for sea snakes caught in the Northern prawn Fishery. Final report on FRDC Project 2005/051. Tech. rep., CSIRO, Cleveland

44. Mouysset L, Doyen L, Jiguet F (2014) From population viability analysis to coviability of farmland biodiversity and agriculture. Conservation Biology 28(1):187-201

45. Mouysset L, Doyen L, Pereau JC, Jiguet F (2014) Benefits and costs of biodiversity in agricultural public policies. European Review of Agricultural Economics DOI 10.1093/erae/jbu005

46. Pascoe S, Vieira S, Dichmont CM, Punt AE (2011) Optimal vessel size and output in the Australian northern prawn fishery: a restricted profit function approach. Australian journal of agricultural and resource economics 55(1):107-125

47. Pauly D, Christensen V, Dalsgaard J, Froese R, Torres Jr F (1998) Fishing down marine food webs. Science 279(5352):860-863

48. Pitcher CR, Burridge CY, Wassenberg TJ, Hill BJ, Poiner IR (2009) A large scale BACI experiment to test the effects of prawn trawling on seabed biota in a closed area of the Great Barrier Reef Marine Park, Australia. Fisheries Research 99(3):168-183

49. Punt AE, Deng RA, Dichmont CM, Kompas T, Venables WN, Zhou S, Pascoe S, Hutton T, Kenyon R, van der Velde T, et al (2010) Integrating size-structured assessment and bioeconomic management advice in Australia's Northern Prawn Fishery. ICES Journal of Marine Science: Journal du Conseil 67(8):1785-1801

50. Punt AE, Deng RA, Pascoe S, Dichmont CM, Zhou S, Plagányi ÉE, Hutton T, Venables WN, Kenyon R, van der Velde T (2011) Calculating optimal effort and catch trajectories for multiple species modelled using a mix of size-structured, delay-difference and biomass dynamics models. Fisheries Research 109:201-211

51. Raudzens E (2007) At sea testing of The Popeye Fishbox bycatch reduction device onboard the FV Adelaide Pearl for approval in Australia's Northern Prawn Fishery. Tech. rep., Australian Fisheries Management Authority, Canberra, Australia.

52. Sainsbury KJ, Punt AE, Smith ADM (2000) Design of operational management strategies for achieving fishery ecosystem objectives. ICES Journal of Marine Science: Journal du Conseil 57(3):731-741

53. Seijo JC, Caddy JF (2000) Uncertainty in bio-economic reference points and indicators of marine fisheries. Marine and Freshwater Research 51(5):477-483

54. Stobutzki IC, Miller MJ, Jones P, Salini JP (2001) Bycatch diversity and variation in a tropical Australian penaeid fishery; the implications for monitoring. Fisheries Research 53(3):283-301

55. Thébaud O, Ellis N, Little LR, Doyen L, Marriott RJ (2014) Viability trade-offs in the evaluation of strategies to manage recreational fishing in a marine park. Ecological Indicators 46:59-69

56. Wassenberg T, Salini J, Heatwole H, Kerr J (1994) Incidental capture of sea-snakes (Hydrophiidae) by prawn trawlers in the Gulf of Carpentaria, Australia. Marine and Freshwater Research 45(3):429-443

57. Woodhams J, Stobutzki I, Vieira S, Curtotti R, Begg GA, (eds) (2011) Fishery status reports 2010: status of fish stocks and fisheries managed by the Australian Government. Tech. rep., Australian Bureau of Agricultural and Resource Economics and Sciences

58. Zhou S, Griffiths SP (2008) Sustainability Assessment for Fishing Effects (SAFE): A new quantitative ecological risk assessment method and its application to elasmobranch bycatch in an Australian trawl fishery. Fisheries Research 91(1):56-68

59. Zhou S, Smith ADM, Punt AE, Richardson AJ, Gibbs M, Fulton EA, Pascoe S, Bulman C, Bayliss P, Sainsbury K (2010) Ecosystem-based fisheries management requires a change to the selective fishing philosophy. Proceedings of the National Academy of Sciences 107(21):9485-9489 


\section{A Bio-economic model}

\section{A.1 Annual spawning stock size indices}

The annual spawning stock size indices $\mathrm{S}_{s}(y(t))$ of the grooved and brown tiger and blue endeavour prawns $(s=1,2$ and 3 , respectively) for the year $y(t)$ are calculated as in [49] and are described in equation (20).

$$
\mathrm{S}_{s}(y(t))=\frac{1}{52} \sum_{t=52(y(t)-1)+1}^{52 y(t)} \beta_{s}(t) \sum_{l} \gamma_{s, l} \frac{1-\exp \left(-Z_{s, l}(t)\right)}{Z_{s, l}(t)} \mathrm{N}_{s, q_{,}, l}(t) .
$$

where $\mathrm{N}_{s, \rho, l}(t)$ is the abundance of prawns of species $s$ of sex $x=$ (for female) in size-class $l$ alive at the start of time $t$ which corresponds to one time step (i.e. one week). Grooved and brown tiger prawns are represented by 1-mm size-classes between lengths of 15 to $55 \mathrm{~mm}$, while blue endeavour prawns are modeled as a single aggregated length class. $y(t)$ is the year ${ }^{8}$ corresponding to the time $t, \beta_{s}(t)$ measures the relative amount of spawning of species $s$ during the time $t$, and $\gamma_{s, l}$ corresponds to the proportion of females of species $s$ in size-class $l$ that are mature. $Z_{s, l}(t)$ is the total mortality on animals of species $s$ in size-class $l$ during time $t$ and is defined by:

$$
Z_{s, l}(t)=M_{s}+F_{s, l}(t)
$$

with $M_{s}$ the natural mortality of animals of species $s$ and $F_{s, l}(t)$ the fishing mortality of animals of species $s$ and size-class $l$ at time $t$. Details on fishing mortality are given in appendix A.3.

\section{A.2 White banana prawn: an uncertain resource}

Abundance of white banana prawns (species $s=4$ ) appears to be more heavily influenced by the environment than by fishing pressure $[21,40]$ and its year to year availability is highly variable. More specifically, stocks are strongly influenced by weather patterns, generally peaking in years in which there has been high rainfall. It is assumed that spawning stock biomasses of white banana prawns do not influence significantly the stock abundances the following years and that annual environmental influences are independent. Therefore, in the present study, white banana prawn annual biomass is modeled as a uniform i.i.d. random variable:

$$
B_{s}(y(t)) \sim \mathcal{U}\left(B_{s}^{-}, B_{s}^{+}\right), \quad s=4
$$

with $B_{s=4}(y(t))$ the stochastic biomass of white banana prawn for the year $y(t)$, and $B_{s=4}^{-}$and $B_{s=4}^{+}$the uniform law bounds (values are given in Gourguet et al [32]).

\section{A.3 Fishing mortality and catch}

Fishing mortality $F_{s, l, f}(t)$ due to fishing effort of fishing strategy $f$ (with $f=1$ and 2 for the grooved and brown tiger prawn fishing strategies, respectively) on animals of species $s$ in size-class $l$ during time $t$ is given by:

$$
F_{s, l, f}(t)=u_{s}(t) \mathrm{E}_{f}(t), \quad s=1,2,3 \text { and } f=1,2 .
$$

where $\mathrm{E}_{f}(t)$ corresponds to the effort of fishing strategy $f$ during time $t$. Fishing mortality functions $u_{s}$ are detailed in Gourguet et al [32].

Weekly catches $C_{s, l, f}(t)$ of species $s=1,2$ and 3 in length-class $l$ by tiger prawn fishing strategy $f(f=1,2)$; and annual catches $C_{s=4, f=3}(y(t))$ of white banana prawns $(s=4)$ by banana prawn sub-fishery $(f=3)$ for the year $y(t)$ are defined by the system of equations (24):

$$
\left\{\begin{array}{l}
C_{s, l, f}(t)=\sum_{x} v_{s, x, l} \mathrm{~N}_{s, x, l}(t) F_{s, l, f}(t) \frac{1-\exp \left(-M_{s}-\sum_{f=1,2} F_{s, l, f}(t)\right)}{M_{s}+\sum_{f=1,2} F_{s, l, f}(t)} s=1,2,3 \text { and } f=1,2 \\
C_{s, f}(y(t))=q_{s, f} B_{s}(y(t)) \mathrm{E}_{f}^{\mathrm{y}}(y(t)) \\
s=4 \text { and } f=3 .
\end{array}\right.
$$

with $v_{s, x, l}$ the mass of an animal of species $s=1,2$ and 3 and sex $x\left(x=q\right.$ for female, and $x=\sigma^{\gamma}$ for male) in size-class $l, F_{s, l}(t)$ the fishing mortality of animals of species $s$ and size-class $l$ at time $t$, and $\mathrm{E}_{f}^{\mathrm{y}}(y(t))$ the annual effort of fishing strategy or sub-fishery $f$ during year $y(t)$.

\section{A.4 Annual profit}

Gross incomes $\operatorname{Inc}_{f}(y(t))$ for grooved $(f=1)$ and brown $(f=2)$ tiger prawn fishing strategies are calculated from catches $C_{s, l, f}(t)$ of tiger and blue endeavour prawns ( $s=1,2$ and 3$)$, and gross income $\operatorname{Inc}_{f=3}(y(t))$ for banana prawn sub-fishery $(f=3)$ is calculated from catches $C_{s=4, f=3}(y(t))$ of white banana prawns $(s=4)$, as described by equation (25).

$$
\left\{\begin{array}{l}
\operatorname{Inc}_{f}(y(t))=\sum_{t=52(y(t)-1)+1}^{52 y(t)}\left(\sum_{s=1}^{3} \sum_{l} p_{s, l} C_{s, l, f}(t)\right), s=1,2,3 \text { and } f=1,2 . \\
\operatorname{Inc}_{f}(y(t))=p_{s} C_{s, f}(y(t)), \\
s=4 \text { and } f=3 .
\end{array}\right.
$$

\footnotetext{
8 Year $y(t)$ is a function of week $t$, where weeks are numbered $1, \ldots, 52,53, \ldots, 102,103, \ldots$
} 
where $p_{s, l}$ is the average market price per kilogram for animals of species $s=1,2$ and 3 in size-class $l$ (related to five market categories for the tiger prawns and corresponding to an average price for the blue endeavour prawns, as they are represented through an aggregated length-class). Grooved and brown tiger prawns are marketed together as 'tiger prawns' under a common size-dependent price, therefore $p_{s, l}$ are identical for $s=1$ and $s=2$. The average price per kilogram of white banana prawns is denoted $p_{s=4}$.

Total annual profit of the whole fishery $\pi(y(t))$ for year $y(t)$ is then expressed by:

$$
\pi(y(t))=\operatorname{Inc}_{3}(y(t))-c_{3}^{v a r} \mathrm{E}_{3}^{y}(y(t))+\sum_{f=1}^{2} \sum_{t=52(y(t)-1)+1}^{52 y(t)}\left(\operatorname{Inc}_{f}\left(t, \mathrm{E}_{f}(t)\right)-c_{f}^{v a r} \mathrm{E}_{f}(t)\right)-c_{v}^{f i x} \mathrm{~K}(y(t)) .
$$

where $\operatorname{Inc}_{f}\left(t, \mathrm{E}_{f}(t)\right)$ is the annual gross income of fishing strategy $f$ for the time $t$ and related to $\mathrm{E}_{f}(t)$ the fishing effort (expressed in days at sea) of the fishing strategy $f$ during time $t$. $c_{f}^{v a r}$ corresponds to the variable cost for one unit of fishing effort of fishing strategy or sub-fishery $f$, and $c_{v}^{f i x}$ is the annual fixed cost by vessel. Details on costs are given in Punt et al [49] and Gourguet et al [32]. K( $(y(t))$ is the number of vessels involved in the NPF during the year $y(t)$.

\section{B Co-viability approach thresholds}

This appendix displays the values of the biological, economic and sea snake conservation viability thresholds used in sections $4.1,4.3$ and 4.4. More specifically, table 5 displays the threshold values tested in the sensitivity analyses for the spawning stock size indices (section 4.1) and table 6 summarizes the threshold values used in the analyses sections 4.2 to 4.4.

Table 5 Values of the biological thresholds tested in sensitivity analyses. $S_{s}^{\lim }, S_{s}^{\text {pa }}$ and $S_{s}(2010)$ stand for the limit spawning stock size index of species $s$, its spawning stock size index of precaution and its 2010 spawning stock size index level, respectively

\begin{tabular}{llc}
\hline Biological threshold & Species & Value \\
\hline $\mathrm{S}_{s}^{\lim }$ & grooved tiger prawn, $s=1$ & 0.293539 \\
& brown tiger prawn, $s=2$ & 0.234883 \\
& blue endeavour prawn, $s=3$ & 0.128637 \\
\hline $\mathrm{S}_{s}^{\text {pa }}$ & grooved tiger prawn, $s=1$ & 0.4080192 \\
& brown tiger prawn, $s=2$ & 0.3264874 \\
& blue endeavour prawn, $s=3$ & 0.1788054 \\
\hline $0.5 \mathrm{~S}_{s}(2010)$ & grooved tiger prawn, $s=1$ & 0.2594365 \\
& brown tiger prawn, $s=2$ & 0.506 \\
& blue endeavour prawn, $s=3$ & 0.208847 \\
\hline
\end{tabular}

Table 6 Values of the thresholds used in co-viability analyses. $S_{s}^{\min }, \pi^{\min }$ and $C_{\text {snake }}^{\text {max }}$ stand for the minimum spawning stock size index of species $s$, the minimum total annual profit and the maximum sea snake catch, respectively

\begin{tabular}{llc}
\hline Threshold & & Value \\
\hline Biological $S_{s}^{\text {min }}$ & grooved tiger prawn, $s=1$ & 0.2594365 \\
& brown tiger prawn, $s=2$ & 0.506 \\
& blue endeavour prawn, $s=3$ & 0.208847 \\
Economic, $\pi^{\min }$ & & $5,950,000$ (AU\$) \\
Sea snakes conservation, $C_{\text {snake }}^{\max }$ & & 11,000 (individuals) \\
\hline
\end{tabular}

\section{Statistics}

This appendix displays in figure 5 the linear regressions between historical annual sea snake catch $\mathrm{C}_{\text {snake, } f}(y(t))$ by sub-fishery $f$ (with $f=1+2$ for tiger prawn sub-fishery and $f=3$ for banana prawn sub-fishery) and associated annual fishing effort $\mathrm{E}_{f}(y(t))$. Table 7 displays the statistics of these regressions. 


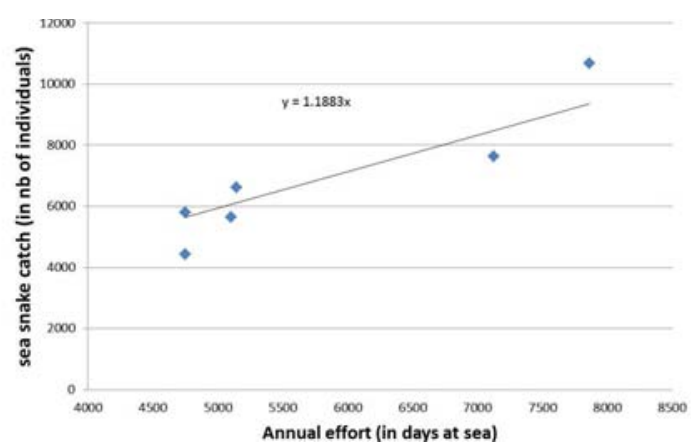

(a) Tiger prawn sub-fishery

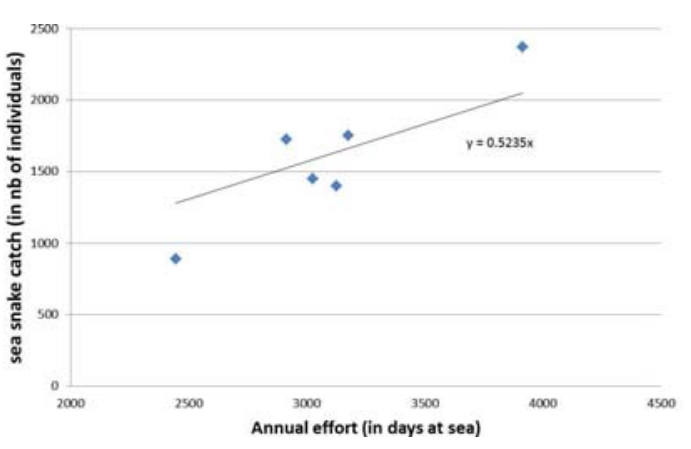

(b) Banana prawn sub-fishery

Fig. 5 Linear regression between historical annual sea snake catch by sub-fishery and associated annual effort. Regression for the tiger prawn sub-fishery is represented in (a) and banana prawn sub-fishery in (b)

Table 7 Statistics of the linear regression between annual sea snake catches by tiger and banana prawn sub-fisheries and associated annual efforts (intercept at 0 )

\begin{tabular}{lcc}
\hline & \multicolumn{2}{c}{ sub-fishery } \\
\cline { 2 - 3 } & tiger $(f=1+2)$ & banana $(f=3)$ \\
\hline Adjusted R Square & 0.785 & 0.778 \\
Residual Variance $\sigma_{f}^{2}$ & 938.98 & 274.25 \\
P-value & $8.843 .10^{-6}$ & $2.687 .10^{-5}$ \\
Coefficient values $a_{f}^{\text {reg }}$ & 1.1883 & 0.5235 \\
\hline
\end{tabular}

